\title{
Out-of-plane failure mechanisms in LFRP composite cutting
}

\author{
C. Santiuste ${ }^{\mathrm{a}}$, H. Miguélez ${ }^{\mathrm{b}, *}, \mathrm{X}$. Soldani ${ }^{\mathrm{b}}$ \\ ${ }^{a}$ Department of Continuum Mechanics and Structural Analysis, Universidad Carlos III de Madrid, Avda. de la Universidad 30,28911 Leganés, Madrid, Spain \\ ${ }^{\mathrm{b}}$ Department of Mechanical Engineering, Universidad Carlos III de Madrid, Avda. de la Universidad 30, 28911 Leganés, Madrid, Spain
}

Keywords:

Carbon LFRP composite

Orthogonal cutting

Numerical modeling

Damage

Out-of-plane failure

\begin{abstract}
LFRP (Long Fiber Reinforced) composites are widely used in structural components for high responsibility applications in different industrial sectors. Composite components are manufactured near final shape, however several machining operations are commonly required to achieve dimensional and assembly specifications. Machining should be carefully carried out in order to avoid workpiece damage. Despite of the interest of numerical modeling to analyze in detail the phenomena involved during composite cut ting, there are only few works in the scientific literature dealing with this topic even in the simple case of orthogonal cutting. Out of plane failure can be accounted only if three dimensional modeling is per formed. However up to date numerical analysis of cutting found in scientific literature was focused in two dimensional approach. In this paper (2D) and three dimensional (3D) numerical modeling of orthog onal cutting of carbon LFRP composite are presented. The aim of the paper is to analyze the complex aspects involved during cutting, including out of plane failure.
\end{abstract}

\section{Introduction}

Productivity and workpiece quality during machining of LFRP composites have become important issues in manufacturing, due to the wide application of this family of materials in different industrial sectors. Although the components are usually made near net shape, achieving dimensional and assembly specifica tions of the workpiece requires cutting operations such as milling [1] and drilling [2].

LFRP lays in the category of "difficult to cut" materials because of the hard and abrasive reinforcement embedded in a polymeric matrix. These materials, commonly used in high responsibility applications, are especially vulnerable to the generation of damage induced during machining. These facts should be accounted when designing the cutting strategy of the composite, in order to control both machining induced damage and tool wear [2].

Experimental research concerning machining of LFRP is not only time consuming and expensive, it is also a potentially health haz ardous due the possibility of contact with skin and/or inhalation of fibers. The use of validated numerical models of composite cutting, offers the possibility of analyzing the mechanisms of damage and other variables without the problems of experimentation.

Despite of the interest of simulation of composite machining, only few works in technical literature deal with finite element analysis of cutting processes. Mainly macro and micro mechanical models and also combined micro macro approaches have been

\footnotetext{
* Corresponding author.

E-mail address: mhmiguel@ing.uc3m.es (H. Miguélez).
}

developed to simulate orthogonal cutting of LFRP composites. Although orthogonal cutting is not an industrial process, it is the objective of numerical analysis due to its simplicity, even in the case of metal cutting [3]. Some examples of the modeling strate gies and damage criteria used in scientific literature for orthogonal cutting of composites can be found in [4 9]. Most of the works re ferred in these works are based in two dimensional (2D) modeling of orthogonal cutting and assume the hypothesis of plane stress. This technique is not suitable for predicting delamination, one of the most important defects induced during machining and related with out of plane stresses. On the other hand, only unidirectional laminate can be modeled, while quasi isotropic laminates are com monly used in structural applications due to their higher perfor mance. Simplified quasi static three dimensional (3D) models of drilling, which consider the drill as a punch, for delamination pre diction, are also found in scientific literature (see for instance [10]).

The interest of improving the knowledge concerning composite cutting has motivated this work, focused on the analysis of out of plane failure in orthogonal cutting of composite. In order to achieve this objective, a new three dimensional finite element (FE) model for orthogonal cutting of composite was developed. Some considerations on the validity of the assumptions involved in the formulation of 2D models are presented. 3D model is applied to simulate orthogonal cutting of quasi isotropic laminate and the influence of stacking sequence is analyzed.

The paper is organized as follows: after a brief introduction, both 2D and 3D FE models are described and the validation, trough the comparison with experimental results obtained from scientific literature, is presented. Numerical results and discussion centered 
on the out of plane failure and on the comparison between both modeling techniques are analyzed in the following section. Finally conclusions remarking the contributions of the paper are presented.

\section{Modeling orthogonal cutting of LFRP composite}

Both two and three dimensional FE models of orthogonal cut ting of composite have been developed using the commercial $\mathrm{Fi}$ nite Element code ABAQUS/Explicit. Conditional stability is the only concern about explicit integration, requiring very small time step. This time is in the order of that required by a dilatational wave to cross the smallest element, leading to large calculation time. Thus the element size should be defined under the point of view of both accuracy and time efficiency of the calculation.

Both 2D and 3D models were validated with the experimental results provided in recent works [11,12], focused on the analysis of orthogonal cutting of the carbon epoxy LFRP composite T300/ 914. The values of experimental cutting forces (in $\mathrm{N} / \mathrm{mm}$ ) are ob tained as the ratio between the average level of the cutting forces and the laminate thickness. The objective is to provide comparable results, taking into account the difficulty of simulating the large thickness considered in experiments because of the large number of elements needed. Thus the results about forces are normalized referring to the force needed to cut a laminate $1 \mathrm{~mm}$ thick, and resultant forces are given in $\mathrm{N} / \mathrm{mm}$. The thickness of the laminate $(6.4 \mathrm{~mm})$ was obtained from the detailed work developed previ ously to [11] by Iliescu [12]. The values of the different material properties needed for the numerical models presented in this work are summarized in the Table 1.

Both 2D and 3D analysis considered rigid tool. The interaction between workpiece and tool was modeled using the algorithm sur face node surface contact available in ABAQUS/Explicit. A constant coefficient of friction equal to 0.5 at the tool/workpiece interface was assumed [9]. Cutting speed was $6 \mathrm{~m} / \mathrm{min}$, the same valued was used in [11].

Table 1

Material properties.

\begin{tabular}{ll}
\hline Carbon epoxy T300/914 & \\
\hline Longitudinal modulus, $E_{1}(\mathrm{GPa})$ & 136.6 \\
Transverse modulus, $E_{2}(\mathrm{GPa})$ & 9.6 \\
In-plane shear modulus, $G_{12}(\mathrm{GPa})$ & 5.2 \\
Major Poisson's ratio, $v_{12}$ & 0.29 \\
Through thickness Poisson's ratio, $v_{23}$ & 0.4 \\
Longitudinal tensile strength, $X_{T}(\mathrm{MPa})$ & 1500 \\
Longitudinal compressive strength, $X_{c}(\mathrm{MPa})$ & 900 \\
Transverse tensile strength, $Y_{T}(\mathrm{MPa})$ & 27 \\
Transverse compressive strength, $Y_{c}(\mathrm{MPa})$ & 200 \\
In-plane shear strength, $S_{12}(\mathrm{MPa})$ & 80 \\
Longitudinal tensile strength, $Z_{T}(\mathrm{MPa})$ & 27 \\
Longitudinal shear strength, $S_{L}(\mathrm{MPa})$ & 80 \\
Transverse shear strength, $S_{T}(\mathrm{MPa})$ & 60 \\
\hline
\end{tabular}

The composite was modeled with an elastic behavior up to fail ure, taking into account the anisotropy of the material. The damage initiation criteria during 2D analysis is based on Hashin's theory $[13,14]$ available in the numerical code. The composite failure cri teria proposed by Hashin includes four failure modes: fiber tensile failure, fiber compressive failure, matrix cracking, and matrix crushing (see Table 2 showing the general formulation of Hashin criteria). 3D modeling involves the prediction of delamination, however this phenomenon is not considered by Hashin theory. Hou model [15] also presented in Table 2, consist of a three failure criteria which consider out of plane stresses. In fiber failure criterion Hou proposed the same formulation under tensile and compressive loading, including longitudinal shear stresses $\sigma_{12}$ and $\sigma_{13}$. In matrix cracking criterion Hou included the transverse shear stress $\sigma_{23}$. Hou also introduced a delamination criterion for tensile out of plane stresses $\left(\sigma_{33}>0\right)$. Hou formulation was imple mented for the 3D analysis through the VUMAT subroutine, devel oped to model the long fiber composite behavior, including a procedure to degrade material properties.

Parameters in Table 2 are the following: $\sigma_{11}, \sigma_{22}$, and $\sigma_{33}$, are the stresses in longitudinal, transverse and through the thickness direction respectively; $\sigma_{12}, \sigma_{23}$, and $\sigma_{31}$, are the shear stresses; $X_{T}$ and $X_{C}$ are the tensile and compressive strengths in longitudinal direction; $Y_{T}$ and $Y_{C}$ are the tensile and compressive strengths in the transverse direction; $Z_{T}$ is the tensile strength through thick ness direction; $S_{L}$ is the longitudinal shear strength; $S_{T}$ is the trans verse shear strength (failure occurs when $d_{i j}$ reaches the value 1 ).

Both models, 2D and 3D FE models, were applied to simulate orthogonal cutting on longitudinal carbon FRP laminates with fiber orientations of $0^{\circ}, 45^{\circ}, 90^{\circ}$ and $45^{\circ}$ (see Fig. 1 for sign conven tion). Moreover, 3D FE model was applied to the analysis of quasi isotropic laminate considering two stacking sequences [45/ 45/0/90]s and [90/0/45/ 45]s.

\subsection{Two dimensional modeling}

A dynamic explicit analysis was developed, with plane stress, quadrilateral, linearly interpolated, elements, with reduced inte gration and automatic hourglass control (CP4SR in ABAQUS/Expli cit notation [16]).

Geometry and boundary conditions of the numerical model are presented in Fig. 1a. Cutting parameters and tool and workpiece characteristics (depth of cut, cutting speed, rake angle, clearance angle, edge radius, laminate architecture) were coherently defined with the experimental work presented in [11,12] used for validation.

The element size was defined in order to achieve both accuracy and time efficiency of the calculation. In a previous work of the authors [17] a sensibility analysis was carried out showing negligi ble differences in numerical results when the element size was $7 \mu \mathrm{m}$ or less. Decreasing the element size from this value would lead to increased computational cost with no significant benefits.

Table 2

Hou and Hashin damage criteria.

\begin{tabular}{lllll}
\hline Failure mode & \multicolumn{2}{l}{ Hou formulation } & Hashin formulation \\
\hline Fiber tension & $d_{f}^{2}$ & $\left(\frac{\sigma_{11}}{X_{T}}\right)^{2}+\left(\frac{\sigma_{12}^{2}+\sigma_{13}^{2}}{S_{L}^{2}}\right)$ & $d_{f t}^{2}$ & $\left(\frac{\sigma_{11}}{X_{T}}\right)^{2}+\left(\frac{\sigma_{12}}{S_{L}}\right)^{2}$ \\
Fiber compression & $d_{f}^{2}$ & $\left(\frac{\sigma_{11}}{X_{T}}\right)^{2}+\left(\frac{\sigma_{12}^{2}+\sigma_{13}^{2}}{S_{L}^{2}}\right)$ & $d_{f c}^{2}$ & $\left(\frac{\sigma_{11}}{X_{c}}\right)^{2}$ \\
Matrix cracking & $d_{m t}^{2}$ & $\left(\frac{\sigma_{22}}{Y_{T}}\right)^{2}+\left(\frac{\sigma_{12}}{S_{L}}\right)^{2}+\left(\frac{\sigma_{23}}{S_{T}}\right)^{2}$ & $d_{m t}^{2}$ & $\left(\frac{\sigma_{22}}{Y_{T}}\right)^{2}+\left(\frac{\sigma_{12}}{S_{L}}\right)^{2}$ \\
Matrix crushing & $d_{m c}^{2}$ & $\frac{1}{4}\left(\frac{\sigma_{22}}{S_{T}}\right)^{2}+\left(\frac{Y_{c} \sigma_{22}}{4 S_{T}^{2}}\right)-\frac{\sigma_{22}}{Y_{C}}+\left(\frac{\sigma_{12}}{S_{L}}\right)^{2}$ & $d_{m c}^{2}$ & $\left(\frac{\sigma_{22}}{2 S_{T}}\right)^{2}+\left[\left(\frac{Y_{c}}{2 S_{T}}\right)^{2}-1\right]\left(\frac{\sigma_{22}}{S_{L}}\right)+\left(\frac{\sigma_{12}}{S_{L}}\right)^{2}$ \\
Delamination & $d_{d e l}^{2}$ & $\left(\frac{\sigma_{33}}{Z_{T}}\right)^{2}+\left(\frac{\sigma_{23}}{S_{T}}\right)^{2}+\left(\frac{\sigma_{13}}{S_{L}}\right)^{2}$ & & \\
\hline
\end{tabular}




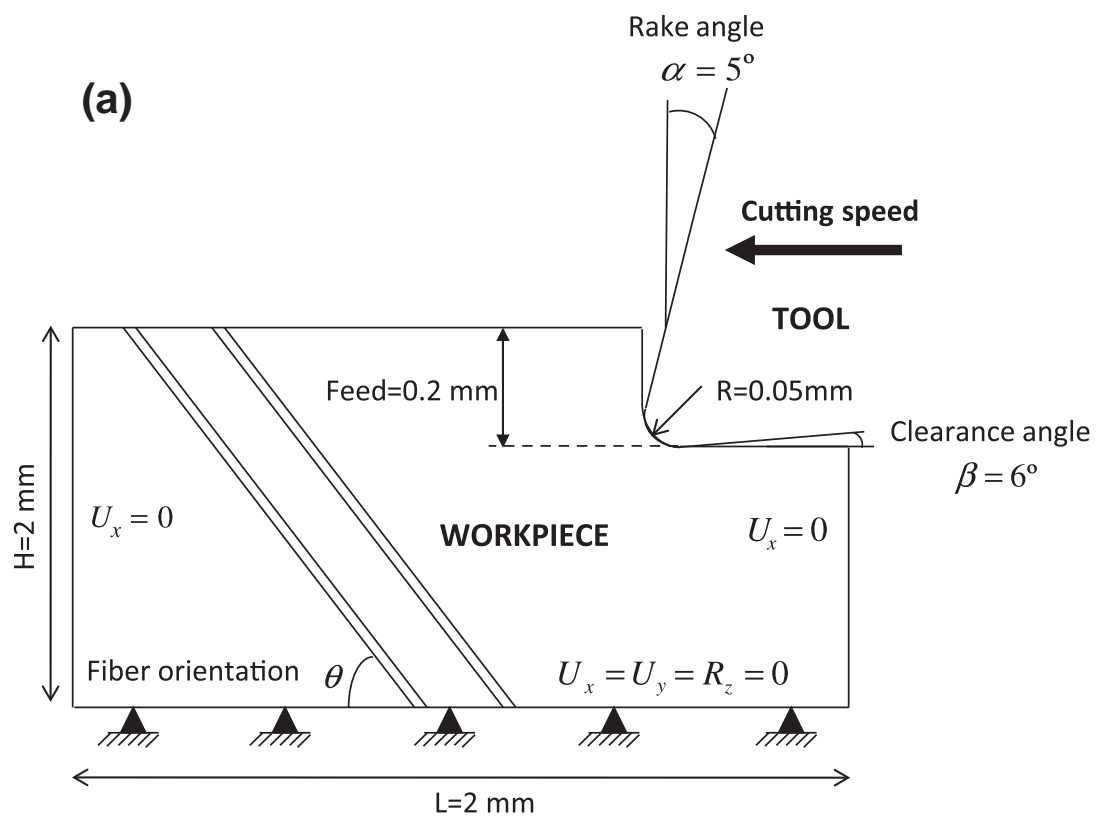

(b)

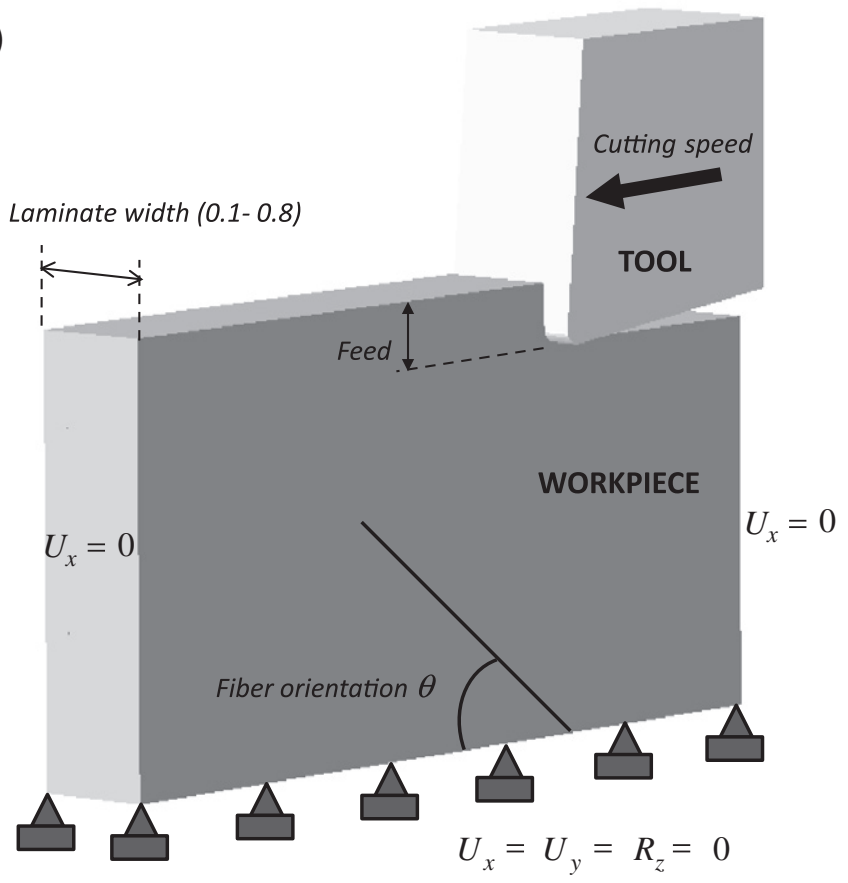

Fig. 1. (a) Scheme of 2D model. (b) Scheme of 3D model.

As was explained previously the Hashin formulation was used to model composite behavior. The stresses at each integration point in the workpiece were computed under a given load. Then, the failure modes were evaluated, since the elastic properties at that element had to be degraded according to the mode of failure if any failure criterion reached the unity. Fiber failure, produced degradation of both longitudinal and shear modulus, and matrix failure produces degradation of transverse and shear modulus.

Damage initiation is associated to the onset of degradation at a material point and is used to predict rupture and subsequent deletion of the damaged element. The degradation of material properties was modeled decreasing the level of the properties related with material stiffness. However the zero value was not stated immediately after the initiation of damage: the energy necessary for complete breakage of the element should be taken into consideration. The statement of this level of energy is very important to simulate the material behavior. When low level of en ergy is considered the element is eroded just after the damage on set, while high level of energy allows high deformation of the element before total breakage.

Although some works in the literature considers just the chip initiation, in this paper complete chip formation is considered. The evolution of chip formation predicted with $2 \mathrm{D}$ model is ana lyzed in detail in a previous work of the authors (see [9]).

\subsection{Three dimensional modeling}

Dynamic explicit analysis was carried out using 8 node brick elements with reduced integration (C3D8R in ABAQUS/Explicit notation [16]). A scheme of the numerical model showing geometry 
and boundary conditions is presented in Fig. 1b. Geometrical char acteristics of the model (tool geometry, feed, cutting length) were the same as those used in 2D approach. The laminate thickness was stated as $0.1,0.4$ and 0.8 in order to analyze the influence of this parameter. Previous sensibility study showed no benefits when the element size was less than $7 \mu \mathrm{m}$, while the computational cost was increased. Thus the element size was $7 \mu \mathrm{m}$ giving enough accuracy and reasonably computational time (around $70 \mathrm{~h}$ for a 3D simula tion in a PC with 12 CPUs).

As was explained before, the VUMAT subroutine implemented Hou formulation for the 3D analysis. Under a given load, the stres ses at each integration point were computed in the user subrou tine. Then, each failure criteria was computed as a function of stresses and if any failure occurs, the material properties at that point are degraded according to the mode of failure. When the fail ure criterion was reached, the stresses in the damaged area were reduced to reproduce the properties degradation. The updated stresses depend on the failure mode: a fiber failure produces the complete collapse of the material at that point $\left(\sigma_{11}=\sigma_{22}=\right.$ $\sigma_{33}=\sigma_{12}=\sigma_{23}=\sigma_{13}=0$ ), whereas a delamination just avoids supporting stresses in the normal direction $\left(\sigma_{33}=\sigma_{23}=\sigma_{13}=0\right)$.

Although cohesive elements are suitable for delamination pre diction, they are not used in this work in order to avoid increasing the complexity of the model: smaller elements would be required to simulate the interface that would lead to increase the computa tional cost.

Elastic properties reduction could lead to distorted elements involving numerical problems, thus the model requires the use of an element erosion criterion. The stresses on an element damaged drop to values close to zero while large deformations appear. These elements do not contribute to the strength or the stiffness of the plate, but they can cause lack of convergence during simulation and instability problems. Erosion criterion based on maximum strain criteria, was implemented in the VUMAT subroutine to re move the distorted elements. After each time increment the longi tudinal strains $\left(\varepsilon_{11}, \varepsilon_{22}\right.$ and $\left.\varepsilon_{33}\right)$ were evaluated, and the element was removed if one of the strains reached a critical value.

Complete chip formation is analyzed in Fig. 2 in terms of cutting force evolution and damage field (matrix crushing). At the beginning of the process, damage is originated at the chip/tool con tact at the zone close to the cutting edge radius. Damage propa gates through the primary shear zone reaching the free surface of the chip. The force level increases rapidly during this phase. During the second phase the damage propagates and the force experiences small drops corresponding with the formation of failure surface. Finally complete chip is formed and a significant drop of the force is observed. This behavior reminds the formation of serrated chip during cutting of thermo resistant alloys with a typical oscillating cutting force.

\subsection{Experimental validation of the models}

Validation of the models was developed by comparing numeri cal predictions of cutting forces with experimental forces observed in the work of Iliescu et al. [11] and Iliescu [12].

Fig. 3a shows the evolution of normalized cutting force (ob tained as the ratio between the level of the cutting forces and the laminate thickness) with 2D and 3D model and experimental results from $[11,12]$ (in this case average value of the experimental force was considered neglecting small signal oscillations) for unidi rectional laminate with fiber angle equal to $45^{\circ}$. Large cutting time corresponding to the complete formation of several chips is ob served, each drop of the curve corresponds with the formation of new chip. The cutting force presented in Fig. 3a corresponds to a laminate width equal to $0.1 \mathrm{~mm}$. Both numerical models showed reasonably accuracy when predicting cutting forces.

Different thicknesses of the 3D laminate were simulated and the cutting force is presented in Fig. 3b (detail of formation of the first chip is shown). Lowest value of the laminate width lead to cutting force profile similar to that predicted by the two dimen sional model, as can be observed in Fig. 3b. For the highest value of thickness, the three dimensional model provided a soft profile of the force similar to that obtained from experimental observations. This result indicates some doubt about the validity of the plane stress hypothesis that can be considered valid just for the limit case of very thin laminate. Similar behavior was observed for other orientations of the fiber.

Fig. 3c shows the normalized cutting force for the quasi isotropic laminates considered and will be commented in the next section.

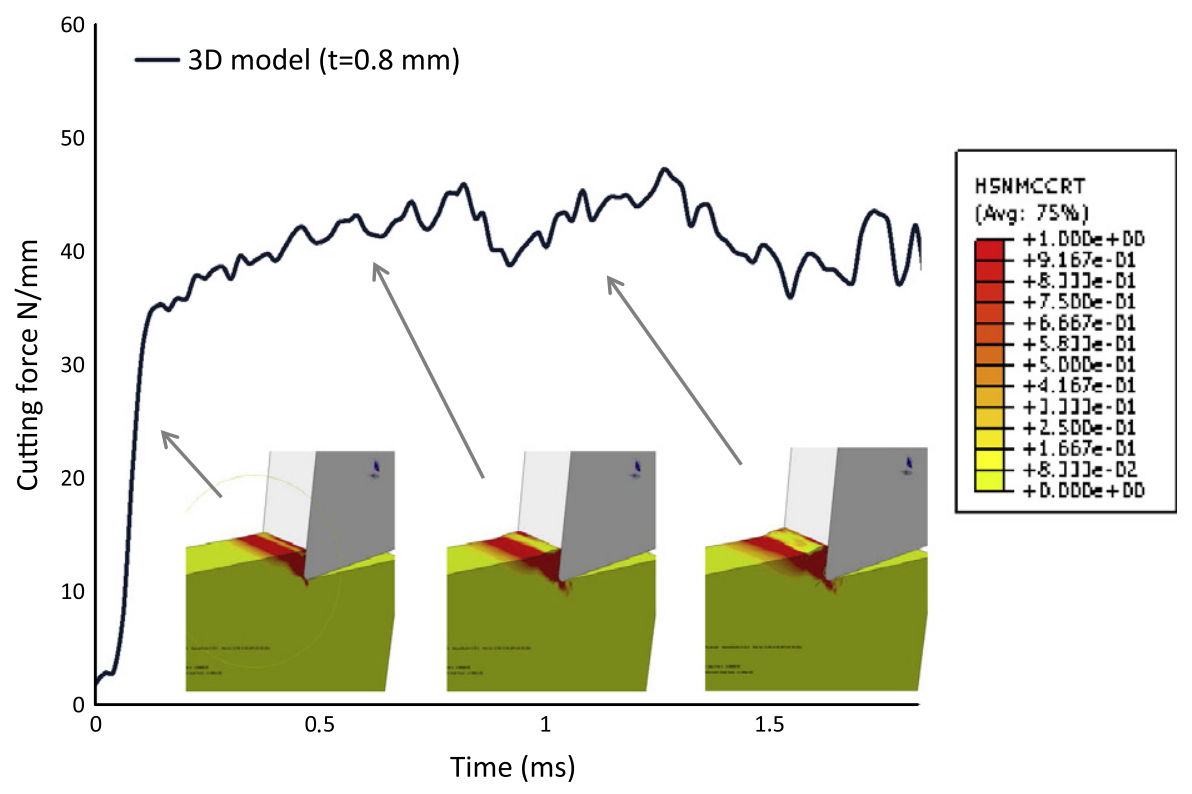

Fig. 2. Evolution of cutting force with chip formation (3D modeling). 

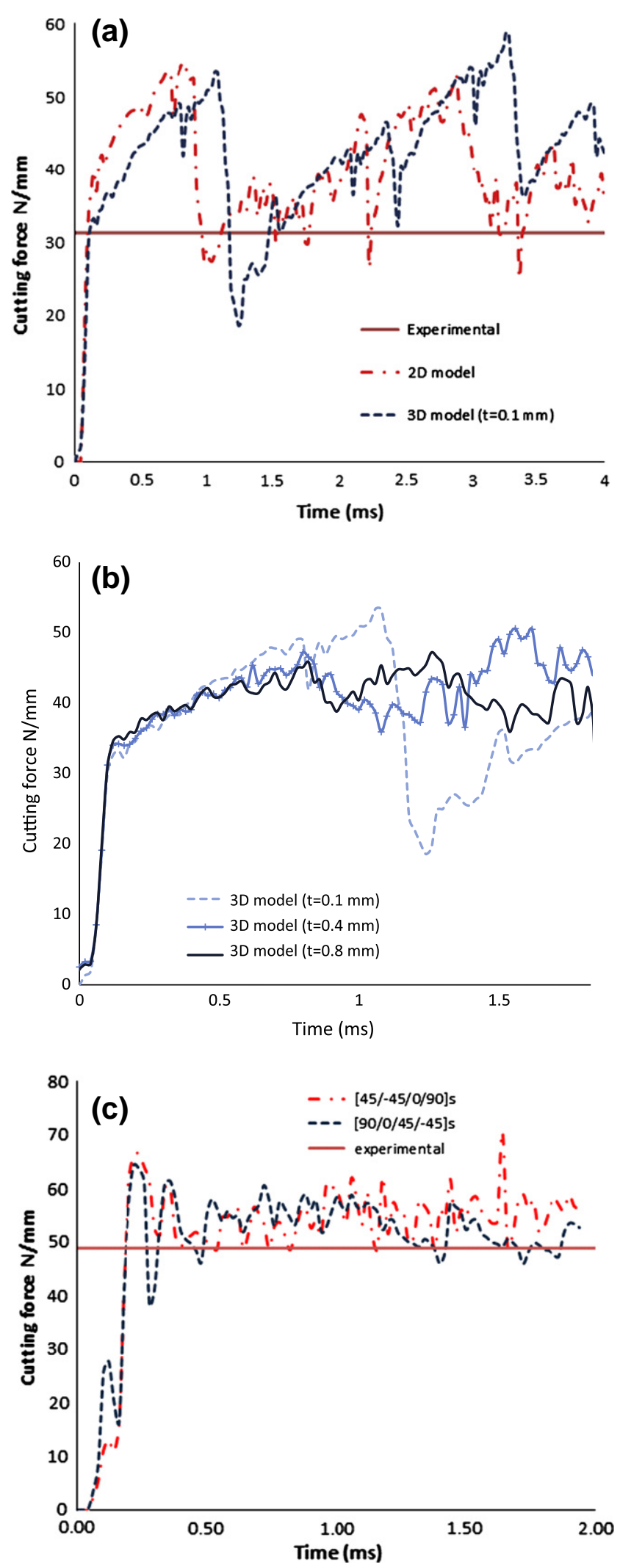

Fig. 3. (a) Cutting force, 2D vs. 3D analysis and experimental [11], (fiber orientation $45^{\circ}$ ). (b) The influence of thickness $t$ on cutting force prediction (fiber orientation $45^{\circ}$ ). (c) Evolution of cutting force for quasi-isotropic laminates (stacking sequence $[45 /-45 / 0 / 90]$ and $[90 / 0 / 45 /-45])$.

\section{Numerical results and discussion}

In this section some numerical results obtained for unidirec tional laminate obtained with both 2D and 3D model are pre sented. Also quasi isotropic laminate is modeled using 3D approach due to the interest of this laminate architecture com monly used in structural applications, instead of unidirectional laminate which has little practical interest.

\subsection{Unidirectional laminate}

Damage fields were obtained with 2D model and 3D model, in the second case corresponding with both inner and external ply. Fig. 4 shows significant differences between the damage developed at external and internal ply. While the extension of damage at the external ply is very similar to that predicted with $2 \mathrm{D}$ model, the in ner ply presents reduced extension of the damage. The effect of the adjacent plies leads to a divergence from the plane stress hypoth esis when an internal ply is considered.

\subsection{Quasi isotropic laminate}

Quasi isotropic laminates are widely used in industrial applica tions. The stacking sequence is carefully selected for high respon sibility applications in order to optimize the material response to service loads. As an example, a sequence with external plies lo cated at $45^{\circ}$ is commonly selected for axial loading (direction $0^{\circ}$ ) of composite bolted joints (see for instance [18]). Joining requires previous drilling of the hole. Also the composite component needs usually contour milling in order to achieve dimensional specifica tions. It is clear the interest of analyzing the behavior of different stacking sequence also during the machining stages previous to the final assembly of the component.

In this section two stacking sequence are analyzed: [45/ 45/0/ $90]$ s and [90/0/45/ 45]s. Although no comparison with experi mental results was possible due to the lack of experimental data for orthogonal cutting of quasi isotropic laminate, and indirect val idation was performed. The level of specific force, available from experimental tests for different orientations of the fiber was approximated for the quasi isotropic laminate as the mean of the values corresponding to each ply considered. The level predicted with the $3 \mathrm{D}(53.5 \mathrm{~N} / \mathrm{mm})$ model corresponded accurately with this experimental approximation $(48.83 \mathrm{~N} / \mathrm{mm})$. Cutting force evolu tion is presented in Fig. $3 c$ with negligible differences between both cases considered.

Fig. 5 shows the damage field at each ply in the first case (lam inate [45/ 45/0/90]s). Significant differences can be observed: the damage is more extended at the external plies $\left(45^{\circ}\right)$ and internal $\left(90^{\circ}\right)$ than at the internal ply located at $0^{\circ}$. It is also presented in the same figure the damage field for the laminate [90/0/45/

45 ]s. As it is observed in the previous case inner layer experi ences reduced damage, corresponding to the orientation $90^{\circ}$.

When both laminates are compared it is clear the influence of the ply location. For instance, the ply oriented at $45^{\circ}$ experiences larger damage when it is located at the surface than when it is at the internal zone of the laminate (see Fig. 5). On the other hand similar level of damage are predicted when the external ply is considered and when the same orientation is simulated with the two dimensional approach. This result indicates that plane stress hypothesis assumed for the formulation of the 2D model is valid for the external ply of the laminate but not for the inter nal zone. 


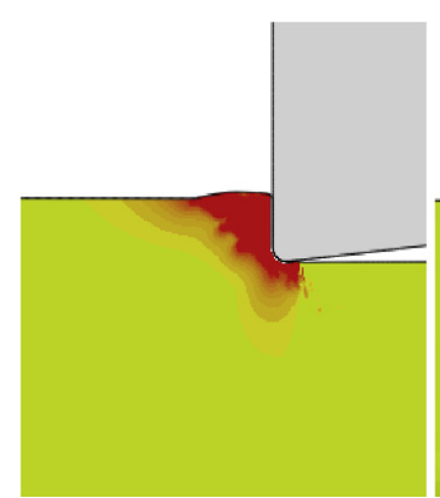

2D Model

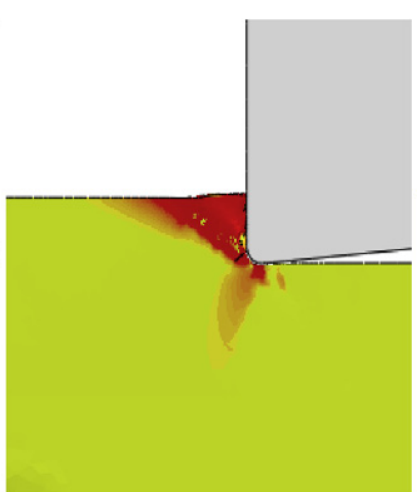

3D model - External ply

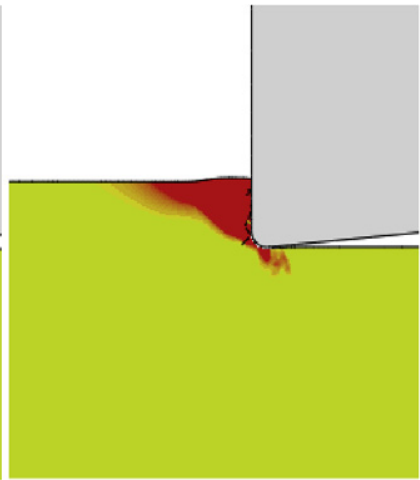

3D model - Internal ply

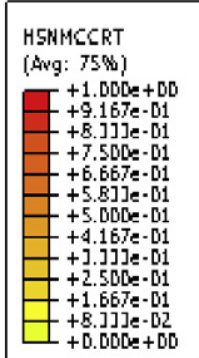

Fig. 4. Damage model (matrix crushing), for fiber orientation $45^{\circ}, 2 \mathrm{D}$ vs. $3 \mathrm{D}$ (thickness of $3 \mathrm{D}$ laminate $t=0.8 \mathrm{~mm}$ ).

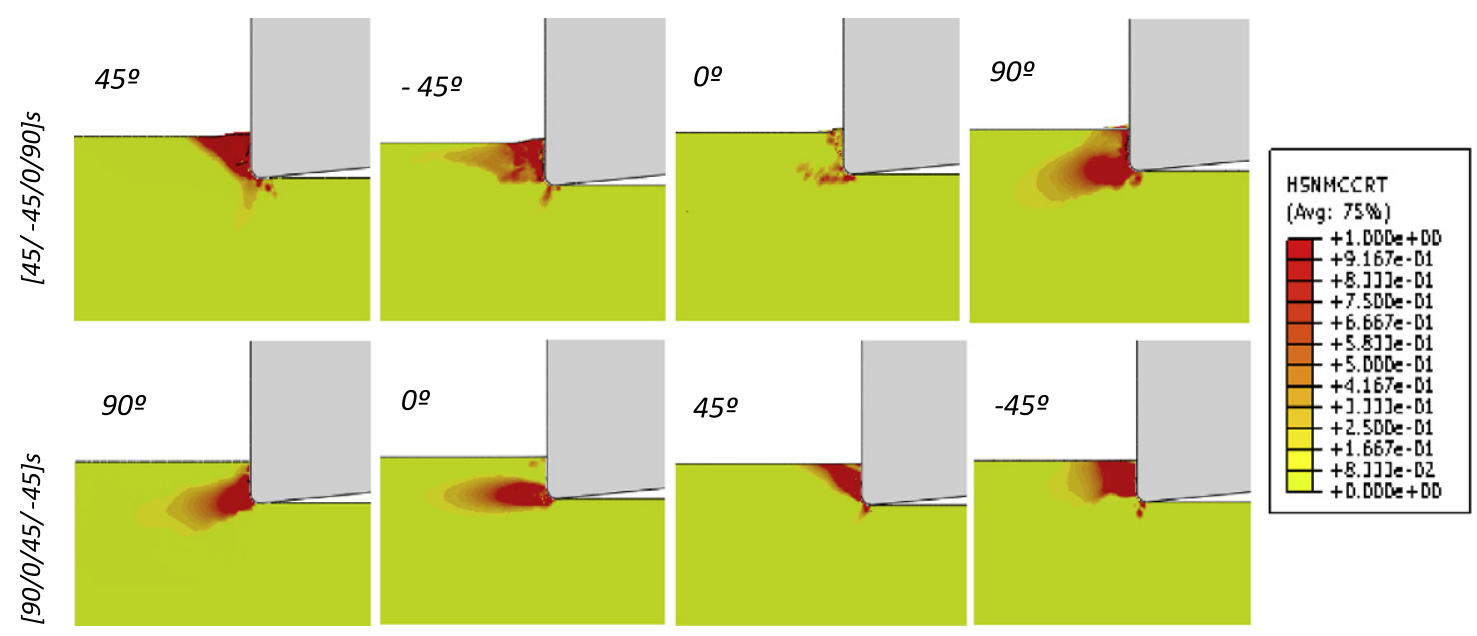

Fig. 5. Damage (matrix crushing) in each ply of both laminates considered (stacking sequences [45/-45/0/90] and [90/0/45/-45]).

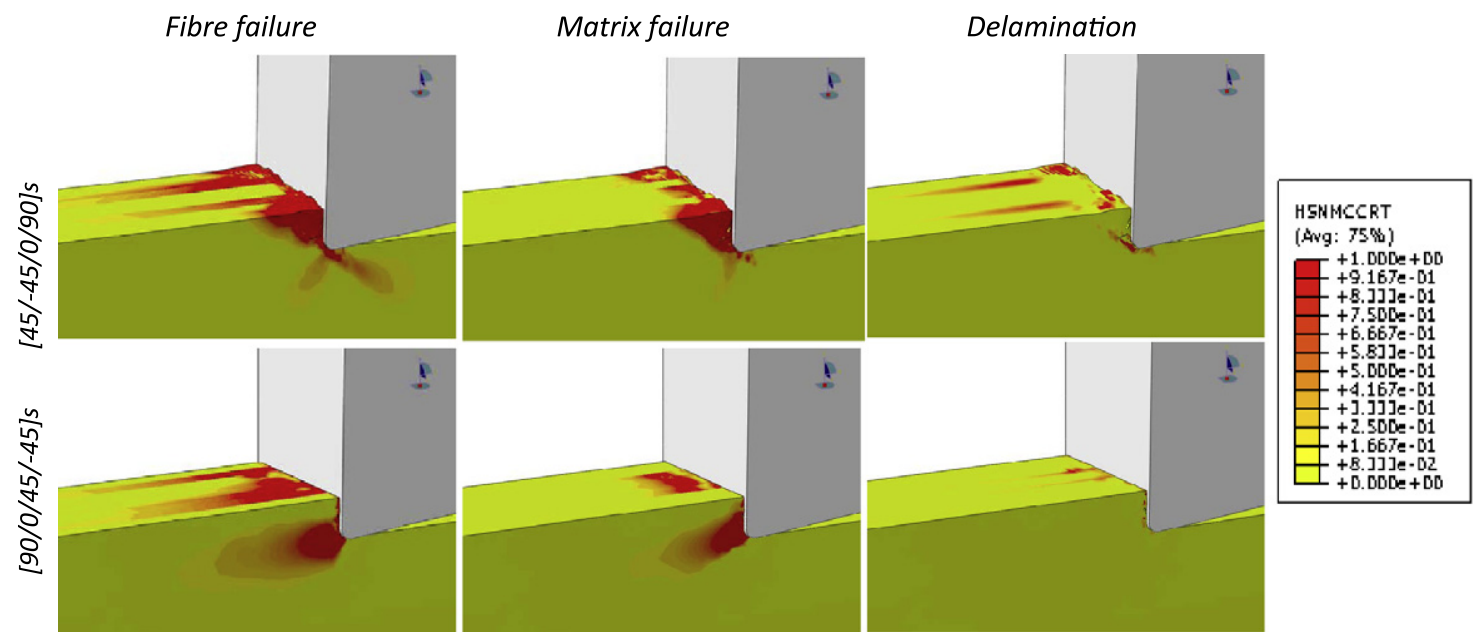

Fig. 6. Fiber compression, matrix crushing and delamination (stacking sequences $[45 /-45 / 0 / 90]$ and $[90 / 0 / 45 /-45]$ ).

Three dimensional approach allows also the prediction of delamination (corresponding with Hou criterion in the model presented in this work). Fig. 6 illustrates fiber (compression) and matrix failure (crushing) and delamination for the stacking sequence [45/ 45/0/90]s. The penetration of the matrix damage in depth beneath the tool tip is significant. It is observed the large extension of the delamination zone ahead of the tool, between the plies oriented at $45^{\circ}$ and $45^{\circ}$. As was explained previously, this configuration is commonly known to give good response to axial loading in direction $0^{\circ}$ and thus it is preferred for bolted joints.

Fig. 7 compares both laminate architectures (stacking sequence [45/ 45/0/90]s and [90/0/45/ 45]s), showing only the damaged areas affected by delamination (elements without damage are 

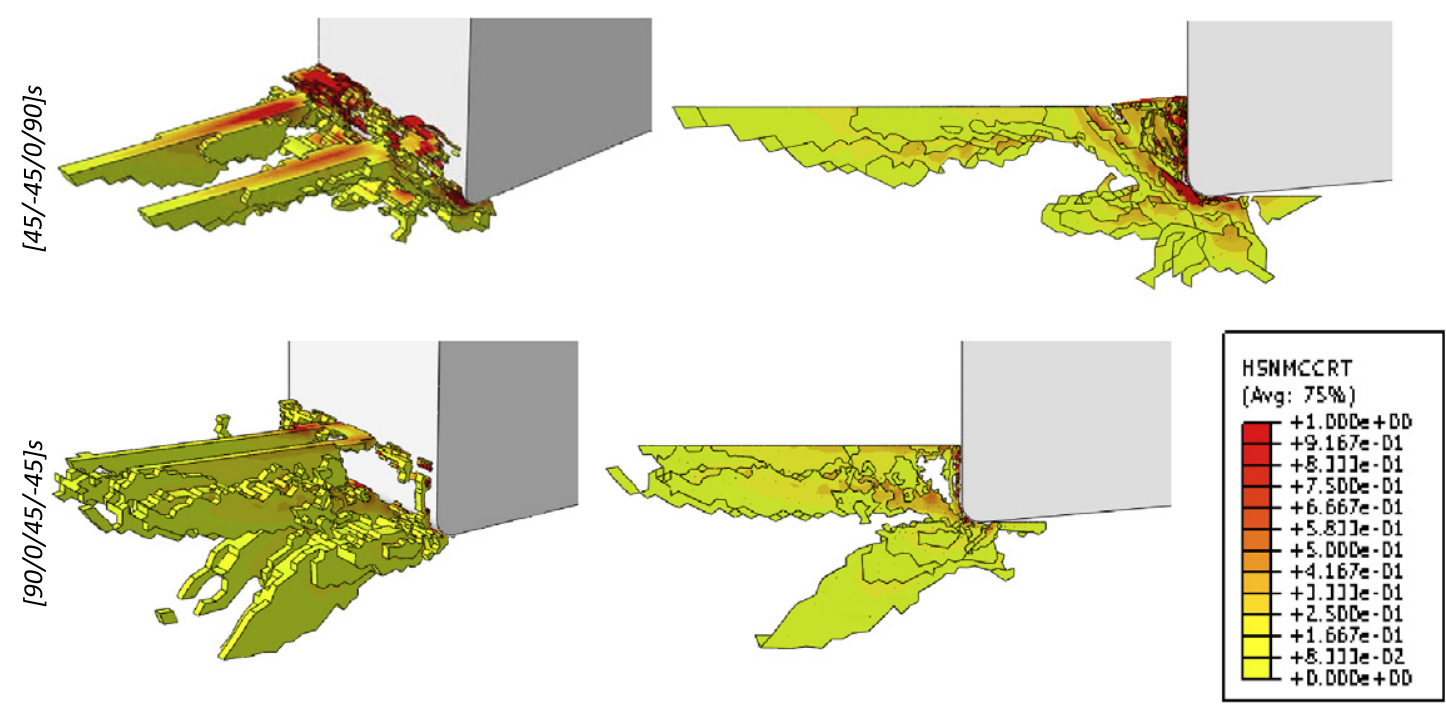

Fig. 7. Areas affected by delamination, only damaged elements are showed (stacking sequences [45/-45/0/90] and [90/0/45/-45]).

removed for clarity). It is possible to observe in the first case larger delamination.

Delamination area is associated to interface between plies with high difference in fiber orientation due to the effect of out of plane shear stresses: delamination propagates through the bisecting direction of the plies fiber orientations [19]. In the analyzed lami nates, interfaces between $45^{\circ}$ and $45^{\circ}$, and between $90^{\circ}$ and $0^{\circ}$ present the greater difference, $90^{\circ}$. Considering that in orthogonal cutting the inner plies present a reduced damaged with respect to the external plies, see Fig. 4, the greater delamination appears at the external interface. Thus in the case of the first laminate the greater delamination is associated to the interfaces between $45^{\circ}$ and $45^{\circ}$ plies, with an orientation of $0^{\circ}$, bisecting of $45^{\circ}$ and $45^{\circ}$. In the second laminate the greater delamination is associ ated to the interfaces between $90^{\circ}$ and $0^{\circ}$ plies, with an orientation of $45^{\circ}$, bisecting of $90^{\circ}$ and $0^{\circ}$.

\section{Conclusions}

In this paper, out of plane failure of LFRP composites during cutting is analyzed comparing both 3D and 2D approaches. Unidi rectional laminate was modeled analyzing the validity of the plane stress hypothesis of the 2D model. Also several aspects, only obser vable with $3 \mathrm{D}$ analysis, such as the simulation of quasi isotropic laminate, the influence of stacking sequence and the development of delamination, are presented. Several conclusions have been de rived from the present work:

- 2D simulations assuming plane stress hypothesis mainly repro duce the phenomena experienced by the external plies of the laminate. 3D simulations showed that the thinner the unidirec tional laminate, the more similar $3 \mathrm{D}$ and $2 \mathrm{D}$ results. These observations indicate the importance of considering out of plane effects during cutting and should be taken into account when analyzing results obtained with 2D modeling.

- 3D approach was applied to the simulation of quasi isotropic laminate and the influence of the stacking sequence on the development of damage was demonstrated. When the plies are located at the free surface they tend to develop larger dam aged zones than when they locate at inner zone of the laminate. This conclusion is important for applications, such as bolted joints, that establish preferable stacking sequence for the dominant loading case. The design of the joint should be devel oped accounting both service loads and the machining process needed by the composite component.

- Delamination was analyzed with 3D approach showing signifi cant extension of this type of failure developed together with matrix and fiber failure. Delamination is one of the most important causes of rejection during final stages of composite components manufacture, thus it should be accounted during modeling of cutting.

Despite of the interest of the results obtained in the work, it could be improved using cohesive elements for delamination mod eling. Also industrial processes should be modeled (mainly milling and drilling) but the base of the analysis and the importance of out of plane failure during cutting have been stated in this work.

\section{Acknowledgement}

The authors are indebted for the financial support of this work, to the Ministry of Science and Innovation of Spain (under project DPI2008 06746).

\section{References}

[1] Kalla D, Sheikh-Ahmad J, Twomeya J. Prediction of cutting forces in helical end milling fiber reinforced polymers. Int J Mach Tool Manuf 2010;50:882-91.

[2] Iliescu D, Gehin D, Gutierrez ME, Girot F. Modeling and tool wear in drilling of CFRP. Int J Mach Tool Manuf 2010;50:204-13.

[3] Molinari A, Cheriguene R, Miguelez H. Numerical and analytical modeling of orthogonal cutting: the link between local variables and global contact characteristics. Int J Mech Sci 2011;53:183-206.

[4] Arola D, Ramulu M. Orthogonal cutting of fiber-reinforced composites: a finite element analysis. Int J Mech Sci 1997;39:597-613.

[5] Nayak D, Bhatnagar N, Mahajan P. Machining studies of UD-FRP composites part 2: finite element analysis. Mach Sci Technol 2005:9:503-28.

[6] Mahdi M, Zhang L. A finite element model for the orthogonal cutting of fiber reinforced composite materials. J Mater Process Technol 2001;113:368-72.

[7] Bhatnagar N, Nayak D, Singh I, Chouhan H, Mahajan P. Determination of machining-induced damage characteristics of fiber reinforced plastic composite laminates. Mater Manuf Process 2004;19(6):1009-23.

[8] Mkaddem A, El Mansori M. Finite element analysis when machining UGFreinforced PMCs plates: chip formation, crack propagation and induceddamage. Mater Des 2009;30(8):3295-302.

[9] Santiuste C, Soldani X, Miguélez H. Machining FEM model of long fiber composites for aeronautical components. Compos Struct 2010;92:691-8.

[10] Durao LMP, de Moura MFSF, Marques AT. Numerical simulation of the drilling process on carbon/epoxy composite laminates. Composites: Part A 2006;37:1325-33. 
[11] Iliescu D, Gehin D, Iordanoff I, Girot F, Gutiérrez ME. A discrete element method for the simulation of CFRP cutting. Compos Sci Technol 2010;70(1):73-80.

[12] Iliescu D. Approaches experimental et numerique de l'usinage a sec des composites carbon/epoxy. PhD thesis; 2008.

[13] Hashin Z, Rotem A. A fatigue criterion for fiber-reinforced materials. J Compos Mater 1973;7:448-64.

[14] Hashin Z. Failure criteria for unidirectional fiber composites. J Appl Mech 1980;47:329-34.

[15] Hou JP, Petrinic N, Ruiz C, Hallett SR. Prediction of impact damage in composite plates. Compos Sci Technol 2000;60(2):228-73.
[16] Hibbit, Karlson, Sorensen Inc. ABAQUS user's manual; 2003 [6.4-1].

[17] Soldani X, Santiuste C, Muñoz-Sánchez A, Miguélez MH. Influence of tool geometry and numerical parameters when modelling orthogonal cutting of LFRP composites. Composites: Part A 2011. doi:101016/i compositesa 2011.04.023

[18] Santiuste C, Barbero E, Miguélez H. Computational analysis of temperature effect in composite bolted joints for aeronautical applications. J Reinf Plast Compos 2011;30(1):3-11.

[19] Abrate S. Impact on composite structures. Cambridge University Press; 1998 